\title{
LINGUAGENS E HIBRIDISMOS
}

Maria Eugênia Curado*

\begin{abstract}
RESUMO: Com o argumento de que todas as linguagens são híbridas, o escopo deste ensaio é propor, fundamentado na teoria das matrizes da linguagem e do pensamento, uma possível aplicação das matrizes sonora, visual e verbal na linguagem cinematográfica. Desta forma, serão examinadas duas sequências do filme $A$ hora da estrela, de Suzana Amaral, baseado em obra homônima de Clarice Lispector.
\end{abstract}

PALAVRAS-CHAVE: Sonoro. Visual. Verbal. Linguagem híbrida. Linguagem cinematográfica.

Com base na lógica das três categorias peircianas e seus pressupostos, Santaella (2001) formula a hipótese de que há três matrizes da linguagem e do pensamento: a sonora, a visual e a verbal. Afirma que a primeira é uma questão de primeiridade, do quali-signo icônico remático, a segunda, de secundidade, sin-signo indicial, discente e a terceira, de terceiridade, do legi-signo simbólico, argumental. Diz ainda que as três matrizes se comportam como "vasos intercomunicantes, num intercâmbio permanente de recursos e de transmutações incessantes" (2001, p. 373). E demonstra, pautada nesse argumento, que não há pureza das linguagens, uma vez que uma absorve a outra, fazendo com que elas se configurem sempre de maneira híbrida. Sendo assim, a estudiosa defende que as linguagens também se hibridizam em cada matriz e, embora cada uma delas se presentifique na outra, as três, de maneira individual, estão no estado mais próximo do puro. A sonora se aproxima do ícone, a visual do índice e a verbal do símbolo.

“Universidade Estadual de Goiás. Imeio: curadoeugenia@hotmail.com.

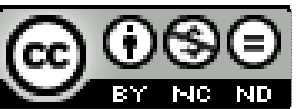

Texto Digital, Florianópolis, v. 8, n. 2, p. 241-255, jul./dez. 2012. ISSNe: 1807-9288 
Por ser uma questão de ícone, a matriz sonora se pauta no acaso, na indeterminação, na vagueza e se liga às formas não representativas, ou seja, possui a qualidade reduzida a si mesma, a marca do gesto e a invariância. A música - linguagem sonora -, aproxima-se do quali-signo, porque, entre a linguagem verbal e a visual, é a mais desprendida do referente, colocando-se, por isso, sob o domínio da primeiridade. A matriz visual, por ser uma questão de índice, fundamenta-se nas ideias de reação e se configura no espaço por meio da ação, determinação, o aqui e agora, o esforço, o choque, a surpresa. A matriz verbal, própria do simbólico, determina-se na generalidade, no crescimento, na inteligência. Nas três matrizes do pensamento e da linguagem, contudo, estão presentes as três categorias fenomenológicas e por isso há, em todas elas, uma qualidade, um existente e uma lei realçados conforme a peculiaridade do universo de cada linguagem.

Com base nessas considerações, o propósito deste trabalho será demonstrar uma possível leitura diagramática da teoria elaborada por Santaella (2001) e sua aplicação na linguagem cinematográfica, especificamente, no filme $A$ hora da estrela (1986), de Suzana Amaral, baseado em obra homônima de Clarice Lispector. Salienta-se, entretanto, que este trabalho tem caráter embrionário, sendo, portanto, o início de um projeto mais ambicioso, isto é, entender de que forma as matrizes da linguagem e do pensamento se comportam nas linguagens híbridas, sobretudo, na cinematográfica.

Este ensaio se realizará em duas etapas. A primeira abordará questões teóricas e a segunda tentará a aplicação das matrizes em duas sequências da película de Amaral. No tocante às proposições de Santaella, parte-se do pressuposto que as matrizes se realizam em um plano horizontal. (Figura 1). Sendo assim, a matriz sonora, a visual e a verbal se consolidam em três blocos formados por em nove lâminas, subdivididos em outros três blocos. 
Tais construções não são compactas e as lâminas formadoras de cada matriz funcionam de forma orgânica e intercambiante, configurando, portanto, as relações híbridas. Examinemos a Figura 1.

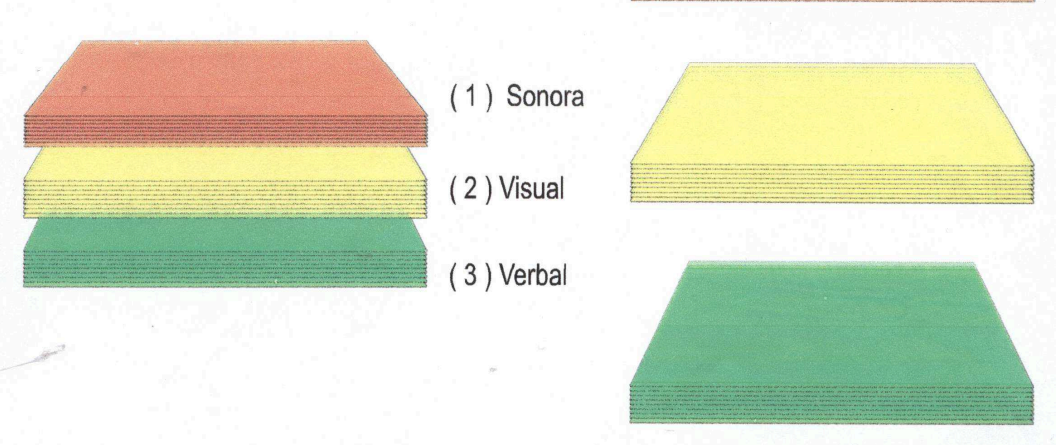

Figura 1 - Matrizes da linguagem e do pensamento

Como se verifica, conceberam-se as matrizes em forma de bloco para que sejam mais bem compreendidas. Salienta-se, contudo, que elas não são elementos estanques e se comunicam como organismos vivos. Cada matriz forma-se por nove lâminas, sendo que quanto mais próximas do primeiro, mais diluídas elas serão, ligando-se, portanto ao sensível e quanto mais próximas do terceiro, mais compactas elas serão e, por isso, aproximam-se da densidade, da razão. Verifica-se tal assertiva nas Figuras 2, 3 e 4.

A matriz sonora (1) (Figura 2) subdivide-se em (1.1) Sintaxes do acaso; (1.2.) Sintaxes dos corpos sonoros; (1.3) Sintaxes convencionais. O primeiro bloco é relativo à sintaxe 1.1, formada pelas lâminas (1.1.1), puro jogo do acaso; (1.1.2) acaso como busca; (1.1.3) modelização do acaso. Nesse caso, a análise verifica o comportamento da linguagem sonora, tendo em vista a predominância do (1), ou seja, do ícone, da primeiridade. As outras três lâminas (1.2) formam o bloco dos corpos sonoros subdivididos em (1.2.1) heurísticas dos corpos sonoros, ou seja, a organização dos sons; (1.2.2) dinâmica das gestualidades; (1.2.3) som e abstrações, 
ligam-se, portanto, ao índice, à secundidade. As outras três lâminas (1.3.1) ritmo que se liga às convenções e é a mais próxima do (1); (1.3.2) melodia, se configura no equilíbrio, uma vez que possui os três elementos; (1.3.3) harmonia que tem a predominância do (3), ou seja, das convenções, do símbolo, da terceiridade. Entretanto, apesar da matriz sonora ter traços (2) e (3) ela se fundamenta no (1). Embora o som seja o fenômeno dessa matriz, nela existe a qualidade, o existente e a lei. Verifica-se, portanto, que a música tem o aspecto de secundidade e da terceiridade, mas seu princípio é o da qualidade. Considerando que a matriz sonora se fundamenta no primeiro, mas que é perpassada pelo segundo e pelo terceiro, o que nos interessa é compreender de que forma essas "lâminas" se comportariam em uma determinada música. Esse assunto será tratado adiante.

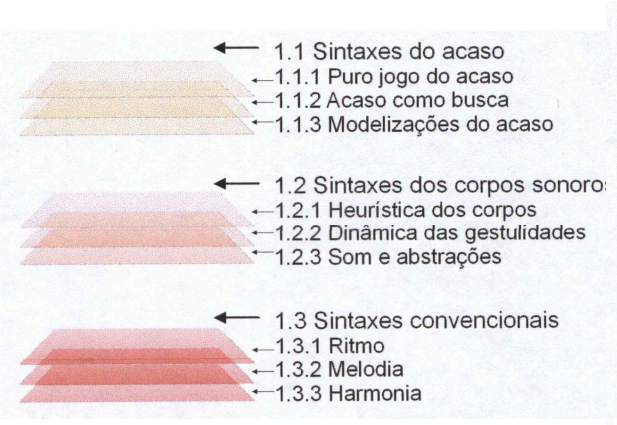

Figura 2 - Matriz sonora

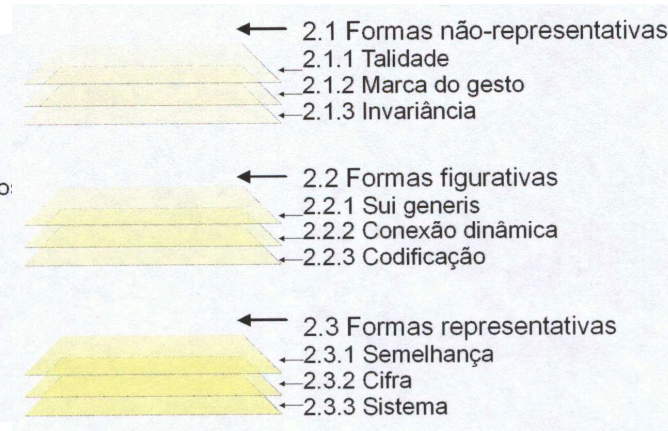

Figura 3 - Matriz visual

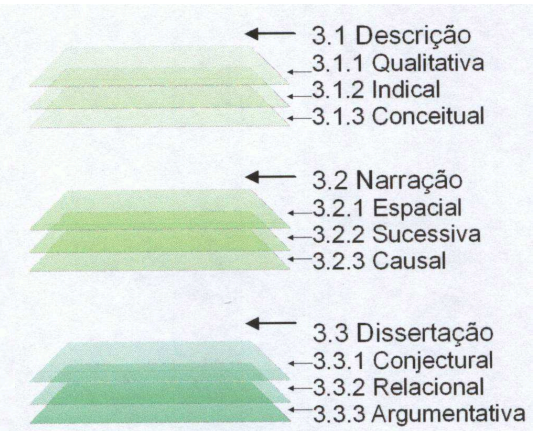

Figura 4 - Matriz verbal

Na matriz visual (2), (Figura 3), o eixo da visualidade está nas formas e se fundamente no segundo. Observa-se que em todas elas há a presença do (2). O primeiro bloco (2.1) é o das formas não representativas que se organiza em (2.1.1), na talidade que é pura realidade qualitativa, mera possibilidade formal e podem se presentificar em qualquer mídia, inclusive na fotografia, por meio, por exemplo, do zoom; (2.1.2) a marca do gesto ou a qualidade materializada; (2.1.3) a invariância ou as leis naturais da qualidade. As formas figurativas (2.2) registram uma parcela da realidade visível. São uma experiência colateral do objetos e subdividem em (2.2.1) sui generis, ou seja, possuem a qualidade do irrepetível; (2.2.2) conexão dinâmica, ou seja, a fotografia, o cinema, o vídeo que se realizam com a "revelação" no suporte; 
(2.2.3) codificação que tem a figura como convenção, códigos.. As formas representativas ou simbólicas (2.3) se configuram na (2.3.1) semelhança ou analogia como os ideogramas; (2.3.2) na cifra, ou representação por figuras cifradas; (2.3.3) sistema, ou organizações visuais presentes, por exemplo, nas anotações musicais. Nessas formas representativas (2.3), as figuras não têm correspondência com o mundo real, por isso se correspondem com ele por analogia, por figuração e por convenção. No primeiro caso, assemelha-se à figura de maneira imitativa; de forma figurada, denotativa, ou seja, próxima do referente como os pictogramas; e ideativa sem acesso visual, mas semelhante à idéia que veicula, ou seja, os ideogramas.

A matriz verbal (3), Figura 3, é a mais complexa, porque se estrutura no simbólico e embute os elementos da visual e da sonora. Ela se divide em Descrição (3.1), Narração(3.2) e dissertação(3.3). A primeira, (3.1.1) qualitativa, liga-se às qualidades da palavra, isto é, a sonoridade, o ritmo, aliterações, aproxima-se da música e é a linguagem própria da poesia, e se desdobra em imagética, diagramática e metafórica. A indicial (3.1.2) se centra nos índices e tem portanto, características metonímicas, sugestivas e denotativas. A conceitual (3.1.3) se pauta na forma e na aparência, possuindo apenas traços qualitativos, descrevem com propósitos funcionais, como é o caso dos manuais de instruções ou aparecem como definidores gerais, isto é, ingredientes do texto dissertativo.

A narração (3.2), que é o ato de contar histórias, pode ser espacial (3.2.1), sucessiva (3.2.2) e causal (3.2.3). A primeira é não linear porque cria relações diagramáticas com o tempo, espacializando-o como Grandes sertões: veredas, de Guimarães Rosa. Ela pode ser icônica quando apresenta relação de similaridade entre as seqüências. Tais características podem ser verificadas em A casa de Usher, de Edgar Alan Poe. A narrativa é indicial quando se estrutura por meio de pistas, índices configurados no espaço. Esse tipo é facilmente encontrado nas histórias de detetives como Sherlock Holmes ou Agatha Christie. Já na simbólica, o espaço simboliza alguma coisa. Um exemplo interessante é o conto Onde estivestes de noite, e Clarice Lispector em que 
a narrativa se estrutura em três planos espaciais e dialoga tanto com a pintura $O$ jardim das delícias, de Hyeronimus Bosch quanto com A Divina Comédia, de Dante Alighieri e representa, tal qual ambas, o céu, o purgatório e o inferno.

A segunda possui características de roteirização e os acontecimentos se sucedem no tempo e no espaço. Embora se configure pela lógica da sucessão, ela pode aparecer de maneira descompassada em uma relação cujo tempo da história é diferente do tempo do discurso. Esse caso aparece nas narrativas de flash back ou digressões como Memórias póstumas de Brás Cubas, de Machado de Assis. As de grau zero são aquelas em que o tempo do discurso coincide com o tempo narrado como nos documentários. As narrativas de sucessividade cronológica são aquelas que seguem os acontecimentos passo a passo como nos folhetins, sobretudo, do romantismo. A causal pode ser difusa, imediata ou mediada. A primeira são aquelas que possuem vários pontos de vista, tendo por isso, caráter de indefinição exemplo emblemáticos são os textos de Virgínia Woolf. A imediata é quando a causa se pauta na intriga como a prosa de Eça de Queiroz. E a mediada é aquela que tem um fator que faz a mediação dos acontecimentos. Talvez, Dom Quixote de la Mancha, de Miguel de Cervantes, possa ser analisado sob esse prisma. A terceira se fundamenta em um acontecimento provocador de outro, ou seja, possui uma relação de causa e efeito, de ação e reação. Nesse caso, verificam-se exemplos emblemáticos nas tragédias gregas.

A dissertação (3.3) é a mais próxima do terceiro e se subdivide em conjectural ou hipotética (3.3.1), relacional (3.3.2) e argumentativa (3.3.3). A conjectural se liga ao pensamento abdutivo, por isso mais próxima do raciocínio icônico, isto é, criativo. Ela pode ser flutuante, factual e conceitual. A flutuante "é a arte do achado, o pensamento passeia pelas ideias e agarra a verdade no ar" (Santaella, 2001, p. 355). A conceitual "transita entre os conceitos, sugerindo conclusões inacabadas, suspensas na incerteza diante das coisas da vida e do mundo" (idem, 356) um exemplo dessa modalidade é a letra da música Águas de março, de Tom Jobim: "é pau, é pedra, é o 
fim do caminho, é um resto de toco, é um pouco sozinho". A dissertação relacional (3.3.2) parte do particular para o geral e funda-se nas correspondências do raciocínio indutivo e se apresenta na forma de comentários, de uso de exemplos e de generalizações empíricas. Já a dissertação argumentativa ou interpretativa (3.3.3) é o momento em que "o raciocínio se encontra aos mecanismos do raciocínio dedutivo" (Santaella, 2001, p.361), ou seja, o raciocínio matemático que "parte de uma hipótese cuja a verdade ou falsidade nada tem a ver com o raciocínio, e cujas conclusões são igualmente ideias" (idem:361). Esse tipo de dissertação apresenta três submodalidades: a opinativa, a comparativa e a argumentativa. A primeira se apresenta na forma de opiniões do enunciador sobre aquilo de que trata o seu discurso e depende do repertório daquele que produz o texto. A comparativa tem o raciocínio engendrado na observação das relações ou confronto das proposições com o propósito de determinar uma conclusão. A interpretativa é a forma mais elaborada da dedução e se realiza sob seu diagrama interno. Possui caráter abstrato e generalizante.

Considerando as três matrizes da linguagem e do pensamento e o suporte próprio da linguagem cinematográfica e também o hibridismo que o perpassa, é possível que as matrizes se assentem, de forma amalgamada sobre a película, porém, justapostas e intercambiantes em comunicação constante, dependendo daquilo que veiculam. Verifiquemos as figuras 4 e 5 : 


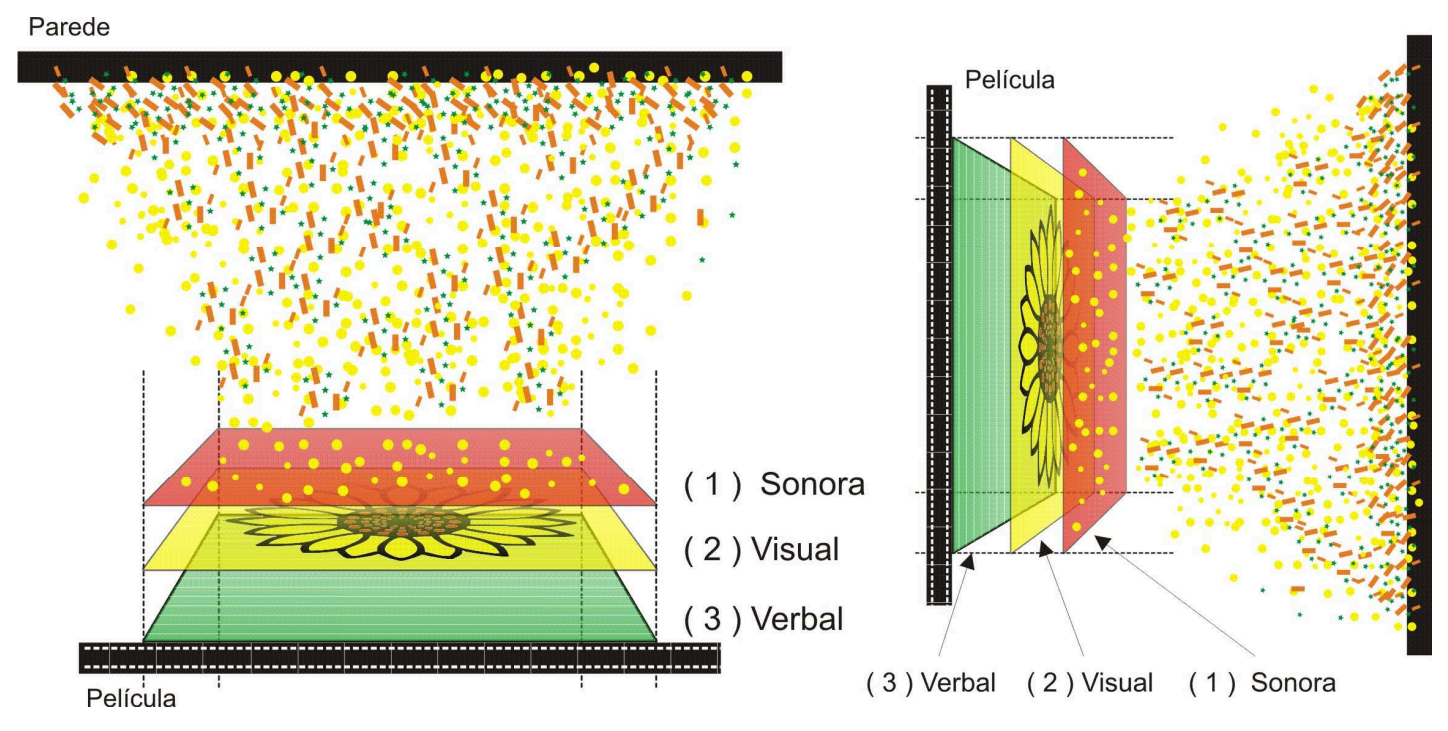

Figura 4 - Matrizes no plano horizontal

Figura 5 - Matrizes no plano vertical

Como se vê, as matrizes, concebidas em um plano horizontal, promovem uma dança interativa entre si com ênfase ora em uma matriz, ora em outra, ou então, em uma relação harmônica entre as três, configurando, portanto, o hibridismo da linguagem e, consequentemente do pensamento que a organizou. Sendo assim, pode-se sugerir que as linguagens teriam níveis de hibridismo, ou seja, quanto mais coerentes forem as relações entre as matrizes mais lineares serão os hibridismos que perpassam aquela linguagem e quanto mais dissonantes, promoveriam um hibridismo de caráter paradoxal. Entende-se, portanto, que "cada caso é um caso". Mas, de maneira geral, o hibridismo se daria pela justaposição, contaminação, empréstimos, diálogos entre as matrizes. Salienta-se, contudo, que ele não se daria somente por meio da sobreposição das matrizes, mas também pelas flutuações e contaminações que acontecem entre as lâminas pelas quais elas são formadas. Diante disso, quanto maior forem os elementos associativos e dialógicos entre as matrizes, mais homogêneo será seu hibridismo, e quanto mais dissonante, mais heterogêneo, sem deixar, entretanto de serem híbridas.

O cinema, pelas características que lhe são próprias, é uma linguagem híbrida, porque se forma juntando som, imagem e palavra. Todavia, sustenta-se, conforme 
Santaella (2001), na matriz verbal, pois tem "vocação narrativa". Além disso, seu caráter discursivo se expressa tanto nos roteiros quanto nos diálogos dos personagens, evidenciados na linguagem verbal oral. Ressalta-se, todavia, que nessa forma de expressão ou arte, o suporte é o acetato de celulose. É ali que se realiza a mistura das matrizes e, consequentemente, o hibridismo da linguagem, que é veiculado em forma de sons e de imagens em movimento.

Assim, mesmo que a base da linguagem cinematográfica seja a matriz verbal, as outras matrizes participam ora mais ora menos da fita e estão presentes no produto final que se realiza em um plano bidimensional, portanto, "refere-se ao visível e tenta, após a pintura e com ela, soluções representativas" (Aumont, 2004, p.68) e, a partir daí, toca na questão do figurativo.

O termo "figurativo" significa a reprodução de formas visíveis ou imaginárias tanto elementos da vida social quanto da mental. Ampliando tal conceito, Aumont (2004) diz que ele se origina de figura, que, por seu turno, procede de fingo que, "entre outras coisas significa, modelar [e que] à ideia de figura existe a de uma mão que modela mesmo nas artes sem mãos como é o cinema" (Aumont, 2004, p.16). Ou seja, o cinema pode representar, moldar, delinear intelectualmente ou reproduzir modelos presentes no mundo exterior ou mental e passa, por conseguinte, a pertencer à matriz visual, ao sin-signo, ao índice, porque ele se realiza no aqui e agora.

Para Martin (2003), a imagem fílmica restitui aquilo que é oferecido à câmera e, por isso, funciona como duplo ao representar réplicas de objetos já existentes. São, pois, por definição, imagens figurativas, em razão de serem visíveis no mundo externo ou de reproduzirem figuras do imaginário. Desse modo, de uma forma ou de outra, as imagens cinematográficas possuem, de certa maneira, vocação mimética, porque "o cinema, ao contar histórias, problematiza a verossimilhança ou o verossímil no sentido de parecer com o real de determinada narrativa" (Campos, 2003, p. 44). 
Ora, se o filme é "uma sequência de fotografias postas em movimento, sonorizadas e projetadas em uma determinada área" Carrière (1995, p.77), se ele é "a visualização da ideia [e] a ideia é apenas um ponto de partida" (Campos, 2003, p. 59), se, é o resultado de "sucessões de etapas imateriais e materiais nas quais as imagens tomam forma" (Calvino, 1998: 99) e restituem, na película, figuras do mundo "real" ou do imaginário, ele pauta-se, por conseguinte, na matriz visual pois ele se realiza no índice, na secundidade, no aqui e agora.

Considerando, também, que há filmes sem roteiros, o cinema seria apenas soluções visuais sobre a celulose. Além disso, mesmo que se fundamente em narrativas, a linguagem cinematográfica é, conforme Pellegrini (2003) demonstrativa, porque as cenas possuem "peso visual e auditivo e se comunicam sem a palavra escrita [e] a imagem tem códigos de interação diversos dos que a palavra escrita [num mundo cuja] cultura [...] é, sobretudo, visual e sua força retórica está na imagem" (Pellegrini, 2003, p. 16).

Assim, enquanto no texto verbal os hipoícones se desvendam "após os leitores atravessarem uma cortina de operações semânticas e sintáticas guiadas por signos materializados em palavras e organizados em conceitos" (Aguiar, 2003, p.120), o cinema desperta reações imediatas pelo seu caráter visual. Essas reações viabilizadas pelas misturas das imagens visuais, da linguagem oral, das onomatopeias, da música e da linguagem escrita para créditos ou títulos, conferem realidade aos filmes. Assim, se, por um lado, a linguagem verbal evoca imagens e organiza uma visão de mundo, por outro, o cinema, por meio da linguagem visual, figurativa e sonora em movimento, e do hibridismo que o configura, faz o mesmo na concretude das películas. De modo que o conteúdo da narrativa fica em segundo plano e é na forma como o cineasta monta os quadros que o filme acontece. Observase, então, que "a imagem cinematográfica existe ao lado do mundo que representa e, embora se mostre parcial, ela tem a mesma natureza visual desse mundo" (Mitry, 2002, p.155), uma vez que cria outro universo, de "diferentes esferas de sentido, [e] a 
imagem total do filme emerge de planos isolados justapostos que possuem uma relação mútua e desta justaposição surge uma terceira imagem" (Eisenstein, 2002, p.18). Além disso, "a imagem fílmica, em montagem narrativa e linear, suscita no espectador um 'sentimento de realidade' e prova a crença e ilusão na existência objetiva do que aparece na tela" (Plaza, 2001, p.146). Desse modo, as imagens projetadas em um plano bidimensional se relacionam com o figurativo, porque são representações do que pode ser visto na realidade exterior e se ligam, de alguma maneira, ao verossímil, porque elas "não são discutidas fora de sua relação com os objetos dos quais são imagens [porque] incorporam aspectos visuais reais de seus objetos, incluindo os seus movimentos. Elas são 'signos' que nos permitem lembrar dos objetos, mas "análogos" dos objetos, seus duplos. (Mitry, 200, p. 154-155). No caso de $A$ hora de estrela (1986), há a tradução da linguagem verbal de Lispector para a visual, mas isso não inviabiliza o figurativo, o verossimilhante, pois ao se analisar a película sob o prima das matrizes, deve-se considerar somente as suas relações em determinada linguagem e não a motivação que levou àquele produto. Ressalta-se, entretanto, que se considera o livro como o princípio à roteirização da película.

O livro A hora da estrela é a história narrada em primeira pessoa por Rodrigo S M., enfocando as angústias pelas quais ele passa durante o processo de construção da narrativa. $O$ texto possui três planos narrativos. $O$ primeiro centra-se no monólogo em que o narrador conduz tanto a ação quanto a reflexão da e sobre a linguagem, tendo como referencial a figura emblemática da nordestina Macabéa. No seguinte, entrelaçadas às suas digressões, o narrador descreve os personagens e suas ações. E, no terceiro momento, Rodrigo S.M. dá a palavra aos personagens. Contudo, no final do texto, retoma as rédeas da narrativa e determina o destino da protagonista, matando-a.

O filme A hora da estrela é a história de Macabéa, uma nordestina semi-analfabeta e sonhadora que se muda para o Rio de Janeiro, em busca de vida melhor. Lá, 
emprega-se como datilógrafa e conhece Olímpico, também nordestino, misto de trabalhador braçal e praticante de pequenos furtos, por quem nutre uma paixão não correspondida. Sonha em ser estrela de cinema e conecta-se ao mundo por meio da Rádio Relógio.

A fita se desenrola em 44 sequências e a análise de seu totem identifica que o filme se fundamenta na Matriz Verbal cuja a submodalidade é a sucessiva, porque se estrutura de maneira cronológica, seguindo a lógica do tempo e do espaço. Isso se dá da primeira à última sequência da fita. As sequências 17 e 18 ilustram essa premissa. Nelas, as matrizes dialogam entre si. A verbal aponta àquilo que deve ser visualizado:

Sequência 17 - Interior, dia seguinte. Quarto de pensão. Sozinha, trancada, dona do quarto, ainda de camisola, Macabéa liga o rádio, com volume bem alto: "Danúbio azul". "Dança" (pula, num ritmo estranho, nem valsa nem nada). O lençol branco envolvendo-a, esvoaçando, leve. Aproxima-se de um grande espelho, onde se vê de corpo inteiro. Ajeita o lençol na cabeça, caindo como um manto: véu de noiva. Olha-se, gosta-se. Admira-se, penas (voz off). "Sou datilógrafa, sou virgem e gosto de Coca-Cola". Corta.
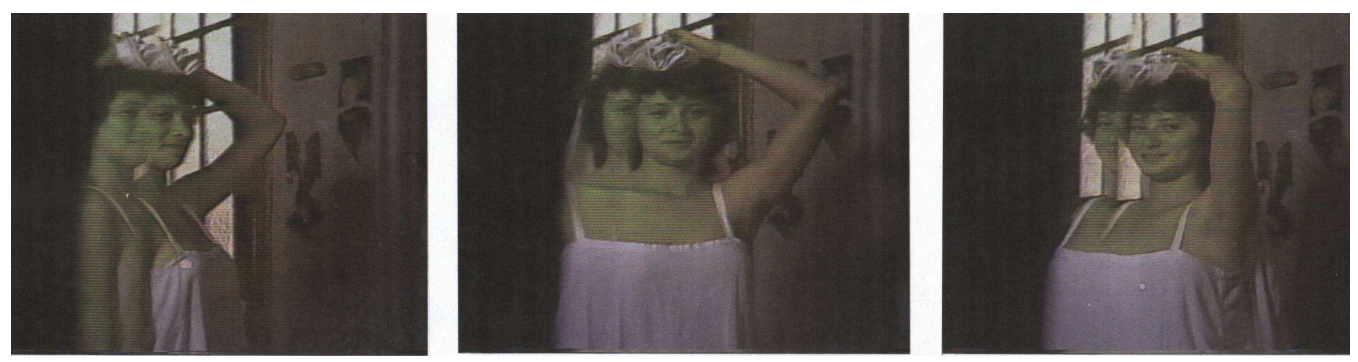

Figura 6 - Quadros da sequência 17

A matriz sonora "amarra" as relações de coerência entre as matrizes. Observa-se, portanto, que escolha da trilha sonora estabelece um elo entre o verbal e o visual, e o contraponto se dá pela desarmonia com que a personagem dança. Diante disso, as fotografias em movimento ilustram os desejos da protagonista idealizados no vestido de noiva e na sua auto afirmação verbal oral em voz off: "Sou datilógrafa, sou virgem e gosto de Coca-Cola" e a sequência 18 aproxima seu ideal da realidade: 
Sequência 18 - Exterior, dia. Manequim com vestido de noiva na vitrine. Macabéa olha, embevecida. Tenta imitar a pose do manequim, desajeitada. "Danúbio Azul" na banda sonora. Corta.

Observa-se, portanto, que há uma sucessão visual lógica que atende às proposições do roteiro. Ou seja, as sequências visuais indicam umas às outras e, sucessivamente enredam a relação narrativo visual da película. Diante disso, considera-se que o hibridismo do filme se estabelece da seguinte forma: Matriz Verbal $\square$ Narração (3.2) =>Sucessiva (3.2.2); Matriz Visual $\square$ Formas figurativas (2.2) $=>$ Conexão dinâmica (2.2.2); Matriz Sonora $\square$ Sintaxes Convencionais (1.3)=> Ritmo (1.3.1)=>Melodia (1.3.2)=> Harmonia (1.3.3) e a lógica que o configura, talvez seja o hibridismo "linear" evidenciado $(1)=>$ narrativa sequencial $=>(2)$ sintaxe convencional $=>(3)=>$ formas figurativas, porque ele acontece por meio das relações de coerência e de harmonia entre as matrizes.

Como se observou, o filme se realiza sobre a película, fundamenta-se em um contexto demonstrativo em relação direta com o duplo, com a figura, entende-se, por conseguinte, que a matriz que o sustenta é a visual fundamentada, entretanto, pela matriz verbal, uma vez que "a narrativa é uma vocação específica do cinema" (Cunha, 2000 , p.17), perpassado pela sonora. No caso do filme de Amaral, ele se fundamenta na narração (3.2),sucessiva (3.2.2) de sucessividade cronológica porque segue os acontecimentos no tempo e no espaço e possui uma lógica linear. Na Matriz Visual (2), dialoga com as formas figurativas (2.2), em conexão dinâmica (2.2.2), perpassada pelas matriz sonora (1) nas Sintaxes Convencionais (1.3), porque a música, "Danúbio Azul" , valsa de concerto, Op. 314, de Johann Strauss Filho, presente na trilha sonora do filme possui, como todas as valsas, o ritmo (3/4), com acento no primeiro tempo. Fundamenta-se na organização sonora e se pauta nas Sintaxes Convencionais (1.3), pois obedece às regras próprias da valsa cujos pilares são o ritmo, a melodia e a harmonia e segue, portanto, as regras do tonalismo. Nota-se que o ritmo está mais próximo do (1), mas é mediado pelo (3). A melodia se equilibra no primeiro, no

\footnotetext{
${ }^{1}$ Essa música, executada pela primeira vez em 1867 é considerada, hoje, o hino nacional da Áustria.
}

Texto Digital, Florianópolis, v. 8, n. 2, p. 241-255, jul./dez. 2012. ISSNe: 1807-9288 
segundo e no terceiro e é mediada e reforçada no terceiro. Danúbio azul, portanto, assim como qualquer valsa se pauta nas convenções, ou seja, segue regras preestabelecidas.

Como se verificou, as matrizes da linguagem e do pensamento propiciam subsídios não só para a análise do hibridismo presente nas mídias audiovisuais como também possibilitam uma previsão das formas híbridas que se deseja veicular. Isso implica dizer que a teoria proposta por Santaella respalda tanto análises de produtos quanto serve de suporte para futuros projetos ou àqueles em desenvolvimento.

\section{LANGUAGES AND HYBRIDISM}

ABSTRACT: Based on the argument that all languages are hybrid, the main goal of this essay is to show, based on the theory of language and mind matrixes, a possible application of the sound, visual and verbal matrixes on cinematographic language. Therefore, two sequences of the film " $\mathrm{A}$ hora da estrela", by Suzana Amaral (based on the homonymous novel by Clarice Lispector) will be examined.

KEYWORDS: Sound. Visual. Verbal. Hybrid language. Cinematographic language.

\section{Referências}

AUMONT, Jacques. As teorias dos cineastas. Tradução de Marina Appenzeller. Campinas: Papirus, 2004.

CALVINO, Ítalo. Seis propostas para o próximo milênio. Tradução de Ivo Barroso. 2. ed. São Paulo: Companhia das Letras, 1998.

CAMPOS, Fernando Coni. Cinema: sonho e lucidez. Rio de Janeiro: Azougue Editorial, 2003.

CARRIÉRE, Jean-Claude. A linguagem secreta do cinema. Tradução de Fernando Albagli e Benjamin Albagli. Rio de Janeiro: Nova Fronteira, 1995.

CUNHA, João Manoel dos Santos. A tradução criativa: A hora da estrela: do livro ao filme. EDUFPEL/ Mundial, 2000. 
LISPECTOR, Clarice. A hora da estrela. 3 ed. Rio de Janeiro: José Olympio, 1978.

MARTIN, Marcel. A linguagem cinematográfica. Tradução de Paulo Neves. São Paulo: Brasiliense, 2003.

MITRY, Jean. In: ANDREW, James Dudley. As principais teorias do cinema: uma introdução (2002). Tradução de Tereza Ottoni. Rio de Janeiro: Jorge Zahar Ed., 2002.

PEIRCE, Charles Sanders. Semiótica. Tradução de José Teixeira Coelho Neto. 3 ed. São Paulo: Perspectiva, 2000.

PELLEGRINI, Tânia, et al. Literatura, cinema e televisão. São Paulo: Editora Senac, Instituto Itaú Cultural, 2003.

Narrativa verbal e narrativa visual: possíveis aproximações. São Paulo:

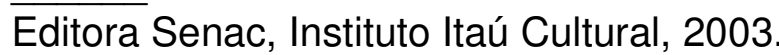

PLAZA, Julio. Tradução intersemiótica. São Paulo: Perspectiva, 2001.

SANTAELLA, Lúcia. O que é semiótica. São Paulo: Brasiliense, 1983.

A percepção: uma teoria semiótica. São Paulo: Experimento. 1993.

A teoria geral dos signos: como as linguagens significam as coisas. São Paulo: Pioneira, 2000.

Matrizes da linguagem e pensamento: sonora visual verbal. São Paulo: lluminuras, 2001.

Semiótica aplicada. São Paulo: Pioneira Thomson Learning, 2002.

Texto recebido em 31/10/2012.

Texto Digital, Florianópolis, v. 8, n. 2, p. 241-255, jul./dez. 2012. ISSNe: 1807-9288 